\title{
The Host-Guest Complexes of Various Carbon Nanotubes (CNTs) and Boron Nitride Nanotubes (BNNTs) with Water at DFT Levels
}

\author{
Leila Afchangi ${ }^{1}$, Mostafa Fazli ${ }^{2, *(D)}$ \\ 1 Department of Chemistry, Semnan University, P.O. Box 35131-19111, Semnan, Iran; li.afchangi@gmail.com (L.A); \\ mfazli@semnan.ac.ir (M.F); \\ * Correspondence: mfazli@semnan.ac.ir (M.F.);
}

Scopus Author ID: 56589721800

Received: 20.04.2021; Revised: 15.09.2021; Accepted: 19.09.2021; Published: 19.11.2021

\begin{abstract}
We have investigated the various nanotube (NT)-water complexes as important host-guest complexes via the DFT method using B3LYP/6-31G* and M06/6-31G* levels of theory. These NTs include single-walled and double-walled carbon nanotubes (SWCNT and DWCNT, respectively). In addition, the boron nitride nanotube (BNNT) and tip-functionalized CNTs are also designed. All geometries turn out as minima on their energy surfaces. Calculated structural and thermodynamic parameters, along with atoms in molecules (AIM) and natural bond orbital (NBO) analyses, indicate that water inside the SWCNTs shows a higher interaction with NT where the nature of interactions is partially electrostatic-partially covalent. Therefore, the SWCNTs turn out as the best candidates for carrying and storage the water molecules.
\end{abstract}

Keywords: Carbon nanotube, Host-guest, DFT.

(C) 2021 by the authors. This article is an open-access article distributed under the terms and conditions of the Creative Commons Attribution (CC BY) license (https://creativecommons.org/licenses/by/4.0/).

\section{Introduction}

A nanotube (NT) is a hollow tube-like structure within the scale of nanometers. Various NTs have been identified, such as carbon nanotubes (CNTs) and boron nitride nanotubes (BNNTs). They were experimentally discovered in 1995 [1]. The CNTs were first discovered in 1991 by Iijima during the direct-current arcing of graphite [2]. This discovery led to many research pieces on CNTs in biology, physics, and chemistry. They have also been produced by plasma arc jets [3,4], decomposition of hydrocarbons [5-11], and pyrolysis [12-16]. CNTs have attracted significant attention for their applications in electronics, nanodevices, drug delivery, and medical imaging in the last years because of their remarkable electronic and mechanical properties [17]. They are also the best water and hydrogen storage candidates through physical and chemical adsorptions [18]. They can be employed as nano-channels to transport biological molecules through cell membranes $[19,20]$. The van der Waals interactions prevent the CNTs from sticking together [21-23]. Typically, the pristine CNTs are insoluble in water [24-31]. To overcome this issue, the functionalization of CNTs has been considered by adding hydrophilic groups. These groups, such as hydroxyl $(\mathrm{OH})$, are added to the open ends of CNTs called tip functionalization [32-39]. Many theoretical studies have been investigated the properties and behavior of CNT and water, which mainly include quantum mechanics (QM) and molecular dynamics (MD) [40-43]. Hummer et al. studied the ability of CNT to carry water molecules [44] in different solvent conditions [45,46]. The impact of tip 
functionalization of CNTs in front of water is less considered up to now. The MD simulation of the interaction between $\mathrm{COOH}$-functionalized CNT and water was reported by Zheng. [47].

Continuing our previous work [48], herein, we investigate the interaction between CNTs and BNNT with a water molecule at DFT levels. Various single-walled carbon nanotubes (SWCNTs) [49-52] and double-walled carbon nanotubes (DWCNTs) [53-56] with different sizes are designed (Table 1).

Table 1. Various NTs designed in this work.

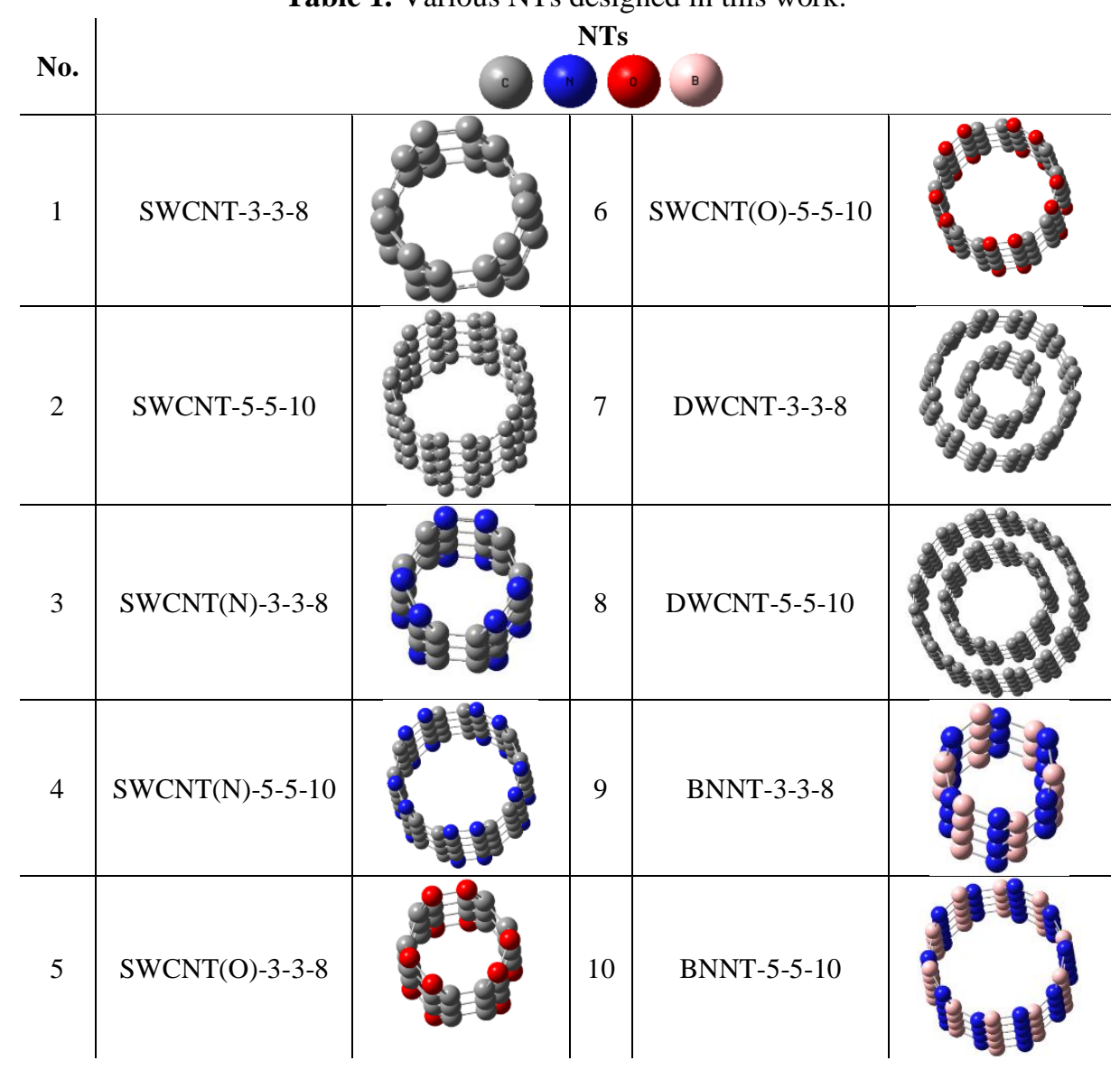

\section{Methods}

Both open ends of NTs are terminated by hydrogens to avoid the boundary effects. All geometry optimizations are carried out at the B3LYP/6-31G* level of theory [57]. Harmonic vibrational frequency calculations are performed to identify the nature of stationary points. All geometries appear minima on their potential energy surfaces for showing no negative force constant (see Supplementary Information). The basis set superposition error [58] (BSSE)corrected interaction energy $\left(E_{\mathrm{int}}\right)$ (using counterpoise method (CP) [59]), binding energy $\left(E_{\mathrm{b}}\right)$, and changes of Gibbs free energy $(\Delta G)$ are calculated at M06/6-31G* level of theory [60-62]. The density of state (DOS) diagrams is depicted via GaussSum software [63]. Structural and thermodynamic parameters such as bond length $(\dot{A})$, bond angle $(\hat{A})$, dipole moment (Debye), symmetry, energy (a.u.), HOMO-LUMO energy gap $\left(E_{\mathrm{g}}\right)$, FT-IR diagram, and electrostatic potential (ESP) maps are determined. Natural bond orbital (NBO) [64] and atoms in molecules (AIM) [65] analyses are performed to scrutinize the nature of interactions between NTs and water. 


\section{Results and Discussion}

We have scrutinized ten numbers of NTs, including CNTs and BNNTs, at DFT levels (Table 1). The CNTs include pristine SWCNTs and their corresponding tip-functionalized isomers $(\mathrm{SWCNT}(\mathrm{N})$ and $\mathrm{SWCNT}(\mathrm{O}))$. Structural and thermodynamic parameters of NTs are calculated at DFT levels of theory (Figures S1-S4 and Table S1).

\subsection{Structural parameters.}

3.1.1. Single-walled carbon nanotube (SWCNT).

Structural parameters such as bond lengths $(\dot{A})$ and bond angles (degree) of SWCNT3-3-8 are depicted in Figure 1.

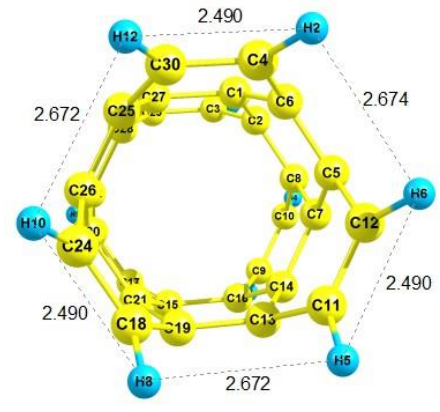

(a)

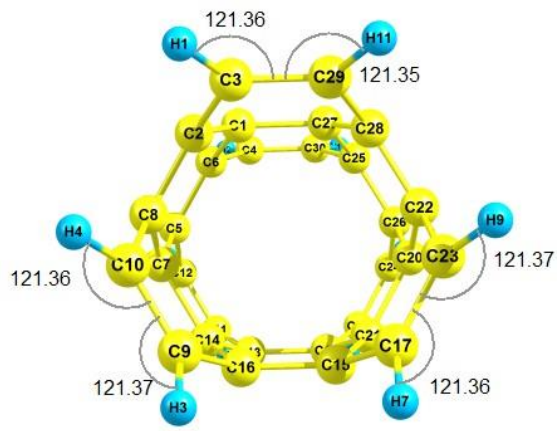

(b)

Figure 1. Calculated (a) bond lengths; (b) bond angles of SWCNT-3-3-8.

To investigate the interaction between NTs and water, we place water at the tips of NTs and inside the NTs. The calculated DOS plot of SWCNT-3-3-8 and water at its tip shows $E_{\mathrm{g}}$ of 0.09752 a.u., which is lower than that of bare SWCNT-3-3-8 (0.09759 a.u.) (Figure 2).

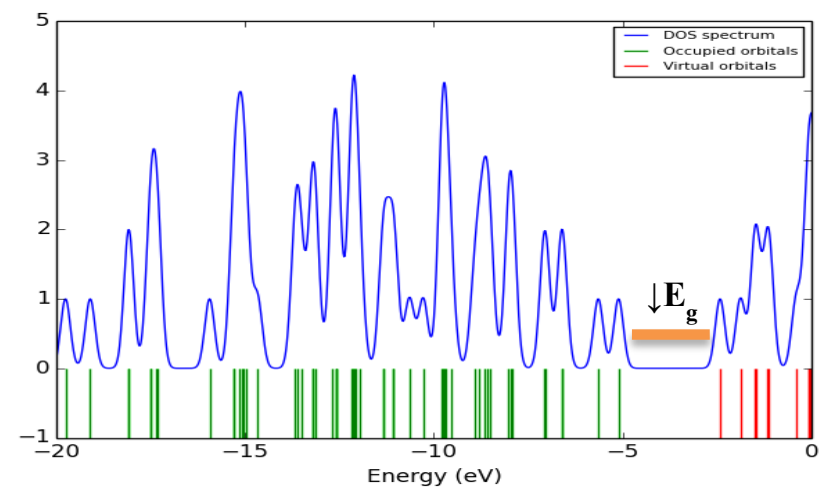

Figure 2. The DOS plot of SWCNT-3-3-8 and water at its tip.

\subsection{Thermodynamic parameters.}

\subsubsection{The $E_{\mathrm{g}}$ values.}

The $E_{\mathrm{g}}$ values of NTs indicate that the functional groups slightly affect the HOMOLUMO energy gap. For example, SWCNT(O)-3-3-8 displays the lowest gap of $E_{\mathrm{g}}(0.09748$ a.u.), which implies more semi-conducting ability than other NTs (Table 2). 
Table 2. Calculated $E_{\mathrm{g}}$ values (a.u.) for NTs

\begin{tabular}{c|c} 
NTs & $\boldsymbol{E}_{\mathbf{g}}$ \\
\hline SWCNT-3-3-8 & 0.09759 \\
\hline SWCNT-5-5-10 & 0.09762 \\
\hline SWCNT(N)-3-3-8 & 0.09751 \\
\hline SWCNT(N)-5-5-10 & 0.09753 \\
\hline SWCNT(O)-3-3-8 & 0.09748 \\
\hline SWCNT(O)-5-5-10 & 0.09750 \\
\hline DWCNT-3-3-8 & 0.09764 \\
\hline DWCNT-5-5-10 & 0.09769 \\
\hline BNNT-3-3-8 & 0.09763 \\
\hline BNNT-5-5-10 & 0.09768
\end{tabular}

\subsubsection{The $E_{\text {int }}, E_{b}$, and $\Delta G$ values.}

Single point calculations are performed to find the total energy of each system at the B3LYP/6-31G* level of theory. The interaction energies $\left(E_{\text {int }}\right)$ between NTs and water are evaluated as follows: $E_{\text {int }}=E_{(\mathrm{NT} / \text { water) }}-E_{(\mathrm{NT})}-E_{\text {(water) }}$. The $E_{(\mathrm{NT} / \text { water) }}, E_{(\mathrm{NT})}$, and $E_{\text {(water) }}$ displays the total energies of host-guest complex (NT and water), NT, and water, respectively (Table $3)$. The $E_{\mathrm{b}}$ can measure the stability and strength of host-guest interaction. The results indicate that the interaction between the host and guest is noncovalent and rather weak.

Table 3. The BSSE corrected interaction energy $\left(E_{\mathrm{int}}\right)$, binding energy $\left(E_{\mathrm{b}}\right)$, and changes of Gibbs free energy $(\Delta G)$ of host-guest complexes ( $\mathrm{kcal} / \mathrm{mol})$.

\begin{tabular}{c|c|c|c} 
Host-Guest Complex (NT and Water) & $\boldsymbol{E}_{\text {int }}$ & $\boldsymbol{E}_{\mathbf{b}}$ & $\Delta \boldsymbol{G}$ \\
\hline SWCNT-3-3-8 & -123.32 & -29.09 & -90.73 \\
\hline SWCNT-5-5-10 & -118.83 & -23.21 & -85.25 \\
\hline SWCNT(N)-3-3-8 & -100.01 & -25.92 & -63.33 \\
\hline SWCNT(N)-5-5-10 & -91.19 & -23.29 & -51.50 \\
\hline SWCNT(O)-3-3-8 & -110.79 & -27.85 & -77.27 \\
\hline SWCNT(O)-5-5-10 & -102.55 & -24.71 & -62.30 \\
\hline DWCNT-3-3-8 & -60.00 & -17.23 & -44.03 \\
\hline DWCNT-5-5-10 & -54.52 & -14.66 & -36.60 \\
\hline BNNT-3-3-8 & -77.64 & -21.58 & -52.93 \\
\hline BNNT-5-5-10 & -71.93 & -19.21 & -47.64
\end{tabular}

The magnitude of $E_{\mathrm{int}}, E_{\mathrm{b}}$, and $\Delta G$ appear consistent. For instance, SWCNT-3-3-8 shows $E_{\text {int }}, E_{\mathrm{b}}$, and $\Delta G$ of $-123.32,-29.09$, and $-90.73 \mathrm{kcal} / \mathrm{mol}$, respectively. The negative values represent highly exothermic interactions toward the formation of host-guest complexes. The NTs with large cavities display lower values. For example, DWCNT-5-5-10 shows the lowest $E_{\mathrm{int}}, E_{\mathrm{b}}$, and $\Delta G(-54.52,-14.66$, and $-36.60 \mathrm{kcal} / \mathrm{mol}$, respectively).

\subsubsection{Frontier molecular orbitals.}

The representations of frontier molecular orbitals of NTs and host-guest complexes along with their corresponding energy gaps, are illustrated (Figures S6-S8). The results indicate that water molecule decreases the energy gap. For example, in SWCNT(O)-3-3-8 and water (host-guest complex), the energy gap reaches from 2.17 to $1.83 \mathrm{eV}$ (Figure 3). 

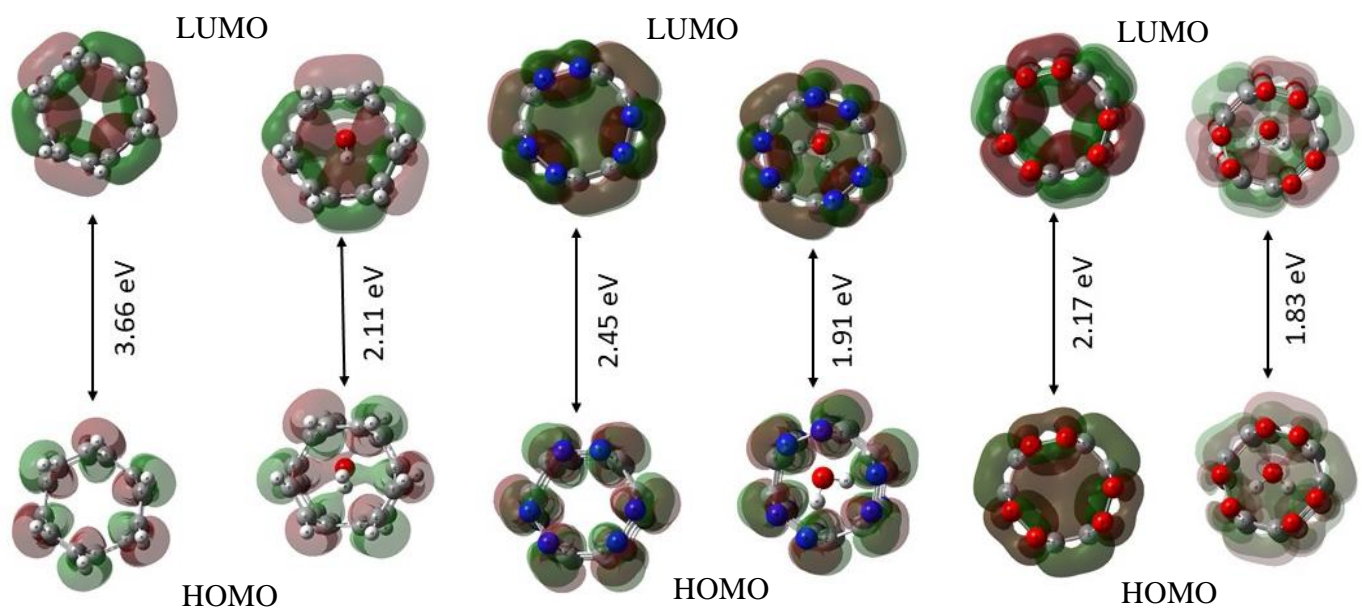

Figure 3. The HOMO-LUMO representations of selected bare CNTs and host-guest complexes (SWCNT-3-3-8, SWCNT(N)-3-3-8, and SWCNT(O)-3-3-8) along with their corresponding energy gap (eV).

\subsubsection{The scatter graph.}

Intermolecular weak interactions can be observed in real space functions (reduced density gradient (RDG) vs. second-largest eigenvalue of Hessian matrix). The green circle of the scatter graph of SWCNT-3-3-8 represents the weak interaction between NT and water (Figure 4).

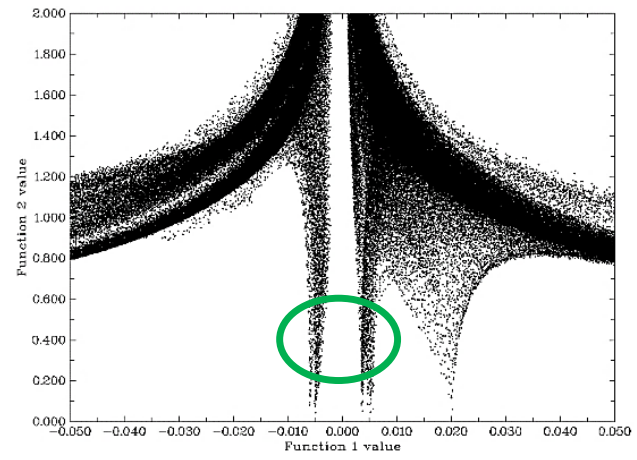

Figure 4. The scatter graph (a.u.) of the most stable host-guest complex (SWCNT-3-3-8).

ESP
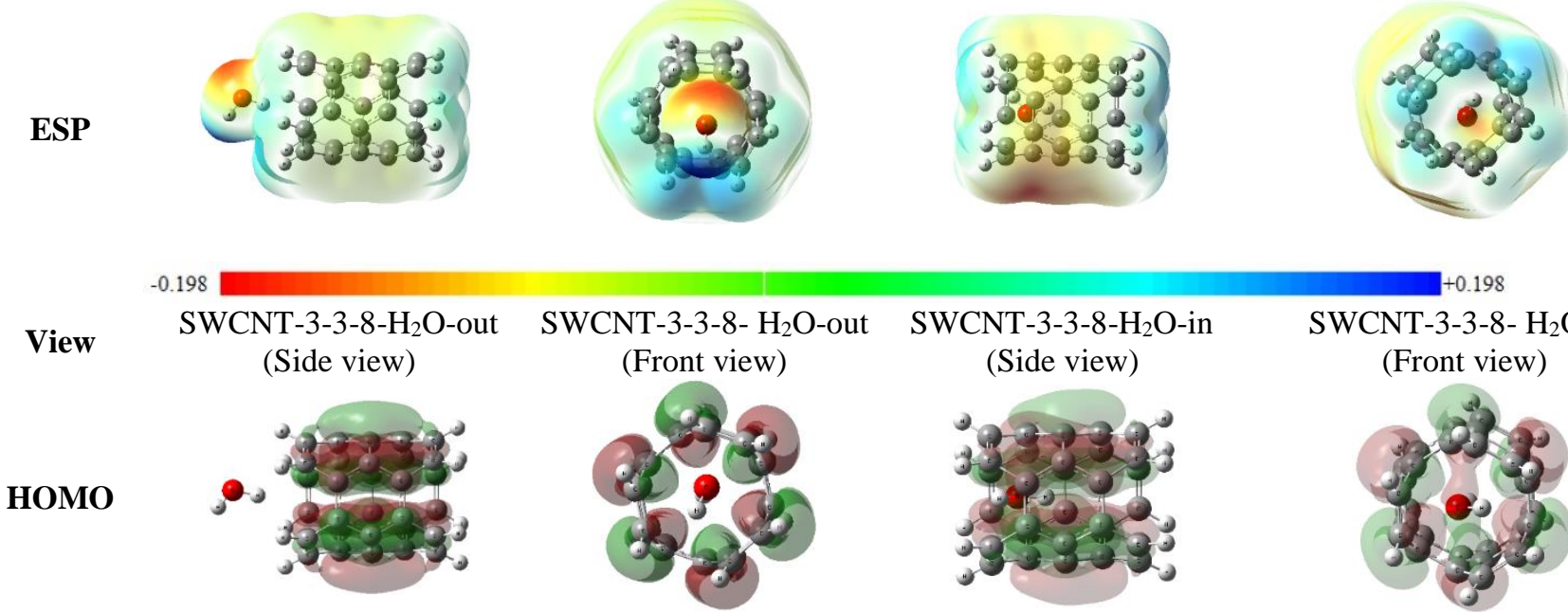
SWCNT-3-3-8- $\mathrm{H}_{2} \mathrm{O}-\mathrm{in}$ (Front view)

ESP maps: Blue and red colors show the electron-deficient and electron-rich regions, respectively (isosurface diagrams are generated with 0.001 a.u. density, and the color scale values are in a.u.).

Figure 5. The ESP maps and HOMO representations of SWCNT-3-3-8 and water. 


\subsubsection{Electrostatic potential maps.}

The ESP maps of the host-guest complex of SWCNT-3-3-8 and water and their corresponding HOMO representations are demonstrated in Figure 5. In the case of water at the tip, the lowest electrostatic potential of the complex is mainly located on water molecules, while it is evenly distributed rather throughout the complex when water is inside the NT. It can be concluded that the latter complex appears more stable.

\subsubsection{The FT-IR spectra.}

To elucidate the formation of host-guest complex, the FT-IR spectra are calculated for pristine SWCNT-3-3-8 and its complex with water-inside (Figure 6). The peak around 3600 $\mathrm{cm}^{-1}$ belongs to the $\mathrm{O}-\mathrm{H}$ vibrational frequency of water that appears after the host-guest complex formation. Furthermore, the resulting spectrum represents extra peaks with respect to the initial one, which confirms the presence of water inside the NT.
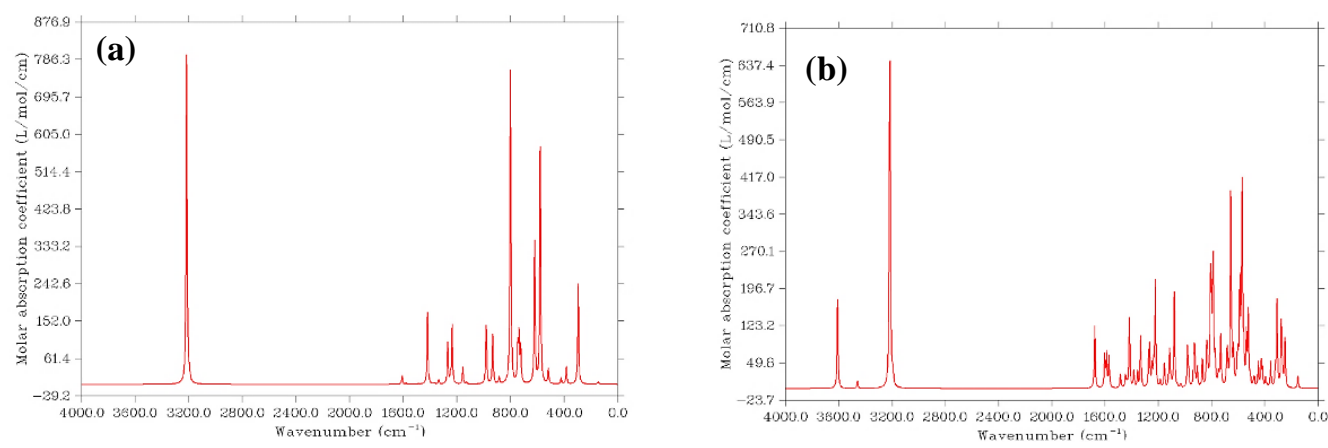

Figure 6. The FT-IR spectra of (a) SWCNT-3-3-8 and (b) SWCNT-3-3-8- $\mathrm{H}_{2} \mathrm{O}-\mathrm{in}$.

\subsubsection{Energies of complexes.}

To compare host-guest complexes' energies $(E)$, their corresponding energies with water-inside are calculated (Table 4). The results show that NTs with larger cavity diameter (5-5-10) display higher energies than 3-3-8 ones. For example, SWCNT(N)-5-5-10 and SWCNT(N)-3-3-8 represent energy values of -1918.34709 and -1918.34714 a.u., respectively.

Table 4. Calculated energies (a.u.) for host-guest complexes (NTs and water)

\begin{tabular}{c|c} 
Host-guest complexes & $\boldsymbol{E}$ \\
\hline SWCNT-3-3-8 & -1226.22145 \\
\hline SWCNT-5-5-10 & -1226.22130 \\
\hline SWCNT(N)-3-3-8 & -1918.34714 \\
\hline SWCNT(N)-5-5-10 & -1918.34709 \\
\hline SWCNT(O)-3-3-8 & -2121.27517 \\
\hline SWCNT(O)-5-5-10 & -2121.27508 \\
\hline DWCNT-3-3-8 & -2613.76821 \\
\hline DWCNT-5-5-10 & -2613.76817 \\
\hline BNNT-3-3-8 & -1402.54023 \\
\hline BNNT-5-5-10 & -1402.54014
\end{tabular}

\subsection{Atoms in molecules (AIM).}

The AIM analysis is performed to identify the nature and strength of interactions between NTs and water via particular parameters such as electron density $\rho(\mathrm{r})$, Laplacian of 
electron density $\nabla^{2} \rho(\mathrm{r})$, and electronic energy density, $H(\mathrm{r})$. Negative values of $H(\mathrm{r})$ and $\nabla^{2} \rho(\mathrm{r})$ imply the partially electrostatic and partially covalent nature of a bond which can be seen for all host-guest complexes (Table 5).

Table 5. The AIM bond critical point data, including electron density $(\rho(\mathrm{r}))$, Laplacian of electron density $\left(\nabla^{2} \rho(\mathrm{r})\right)$, and electronic energy density $(H(\mathrm{r}))$ calculated for selected BCPs of host-guest complexes.

\begin{tabular}{|c|c|c|c|c|}
\hline Host-guest complexes & BCP & $\rho(\mathbf{r})$ & $\nabla^{2} \rho(\mathbf{r})$ & $H(\mathbf{r})$ \\
\hline \multirow{3}{*}{$\begin{array}{c}\text { SWCNT(N)-3-3-8 } \\
\mathrm{H}_{2} \mathrm{O} \text {-in }\end{array}$} & O----C1 & 0.104 & -0.111 & -0.024 \\
\hline & H1----C2 & 0.098 & -0.064 & -0.030 \\
\hline & H2----C3 & 0.133 & -0.050 & -0.066 \\
\hline \multirow{3}{*}{$\begin{array}{c}\text { SWCNT(N)-3-3-8 } \\
\mathrm{H}_{2} \mathrm{O} \text {-out }\end{array}$} & O----N1 & 0.064 & -0.070 & -0.003 \\
\hline & O----N2 & 0.009 & -0.008 & -0.001 \\
\hline & O----N3 & 0.070 & -0.085 & -0.003 \\
\hline \multirow{5}{*}{$\begin{array}{c}\text { SWCNT(N)-5-5-10 } \\
\mathrm{H}_{2} \mathrm{O} \text {-in }\end{array}$} & O----C2 & 0.010 & -0.010 & -0.001 \\
\hline & O----C3 & 0.010 & -0.010 & -0.001 \\
\hline & H1----C1 & 0.010 & -0.010 & -0.002 \\
\hline & H1----C4 & 0.010 & -0.010 & -0.001 \\
\hline & $\mathrm{H} 2----\mathrm{C} 5$ & 0.010 & -0.010 & -0.001 \\
\hline \multirow{5}{*}{$\begin{array}{c}\text { SWCNT(N)-5-5-10 } \\
\mathrm{H}_{2} \mathrm{O} \text {-out }\end{array}$} & $\mathrm{O}----\mathrm{C} 2$ & 0.009 & -0.010 & -0.001 \\
\hline & O----C3 & 0.009 & -0.010 & -0.001 \\
\hline & H1----C1 & 0.008 & -0.010 & -0.002 \\
\hline & H1----C4 & 0.010 & -0.010 & -0.001 \\
\hline & $\mathrm{H} 2----\mathrm{C} 5$ & 0.008 & -0.010 & -0.001 \\
\hline \multirow{3}{*}{$\begin{array}{c}\operatorname{SWCNT}(\mathrm{O})-3-3-8 \\
\mathrm{H}_{2} \mathrm{O}-\text { in }\end{array}$} & $\mathrm{O}----\mathrm{C} 2$ & 0.105 & -0.115 & -0.024 \\
\hline & H1----C1 & 0.136 & -0.045 & -0.069 \\
\hline & H2----C3 & 0.098 & -0.064 & -0.030 \\
\hline \multirow{6}{*}{$\begin{array}{c}\text { SWCNT(O)-3-3-8 } \\
\mathrm{H}_{2} \mathrm{O} \text {-out }\end{array}$} & $\mathrm{O} 1----\mathrm{C} 1$ & 0.011 & -0.010 & -0.001 \\
\hline & O1----C2 & 0.011 & -0.010 & -0.001 \\
\hline & O1----C3 & 0.011 & -0.011 & -0.001 \\
\hline & O1----C4 & 0.011 & -0.011 & -0.001 \\
\hline & H1----O2 & 0.010 & -0.011 & -0.001 \\
\hline & $\mathrm{H} 2----\mathrm{O} 3$ & 0.010 & -0.011 & -0.001 \\
\hline \multirow{4}{*}{$\begin{array}{c}\text { SWCNT(O)-5-5-10 } \\
\mathrm{H}_{2} \mathrm{O} \text {-in }\end{array}$} & $\mathrm{O}----\mathrm{C} 1$ & 0.009 & -0.008 & -0.001 \\
\hline & O----C3 & 0.005 & -0.005 & -0.001 \\
\hline & H1----C2 & 0.008 & -0.008 & -0.002 \\
\hline & H2----C4 & 0.005 & -0.005 & -0.001 \\
\hline \multirow{4}{*}{$\begin{array}{c}\text { BNNT-3-3-8 } \\
\mathrm{H}_{2} \mathrm{O} \text {-in }\end{array}$} & O----B1 & 0.008 & -0.008 & -0.001 \\
\hline & O----B3 & 0.005 & -0.005 & -0.001 \\
\hline & H1----N2 & 0.008 & -0.008 & -0.002 \\
\hline & H2----N4 & 0.005 & -0.005 & -0.001 \\
\hline \multirow{3}{*}{$\begin{array}{c}\text { BNNT-3-3-8 } \\
\text { H }_{2} \mathrm{O} \text {-out }\end{array}$} & O----H3 & 0.020 & -0.020 & 0.000 \\
\hline & O----H4 & 0.034 & -0.034 & 0.000 \\
\hline & O----H5 & 0.037 & -0.041 & -0.001 \\
\hline \multirow{5}{*}{$\begin{array}{c}\text { BNNT-5-5-10 } \\
\mathrm{H}_{2} \mathrm{O} \text {-in }\end{array}$} & O----N1 & 0.010 & -0.010 & -0.001 \\
\hline & O----N2 & 0.010 & -0.010 & -0.001 \\
\hline & H1----N3 & 0.010 & -0.010 & -0.001 \\
\hline & H1----N4 & 0.010 & -0.010 & -0.001 \\
\hline & H2----N5 & 0.005 & -0.005 & -0.001 \\
\hline \multirow{4}{*}{$\begin{array}{c}\text { BNNT-5-5-10 } \\
\text { H }_{2} \mathrm{O} \text {-out }\end{array}$} & O----N2 & 0.002 & -0.002 & -0.001 \\
\hline & O----N4 & 0.001 & -0.001 & -0.001 \\
\hline & H1----N1 & 0.002 & -0.002 & -0.001 \\
\hline & H2----N3 & 0.004 & -0.003 & -0.001 \\
\hline \multirow{3}{*}{$\begin{array}{c}\text { SWNT-3-3-8 } \\
\mathrm{H}_{2} \mathrm{O} \text {-in }\end{array}$} & O----C1 & 0.076 & -0.078 & 0.010 \\
\hline & H1----C2 & 0.100 & -0.041 & 0.040 \\
\hline & H2----C3 & 0.140 & -0.033 & 0.080 \\
\hline \multirow{3}{*}{$\begin{array}{c}\text { SWNT-3-3-8 } \\
\text { H }_{2} \mathrm{O} \text {-out }\end{array}$} & H1----C1 & 0.010 & -0.010 & -0.001 \\
\hline & H1----C2 & 0.005 & -0.004 & -0.001 \\
\hline & H1----C3 & 0.005 & -0.004 & -0.001 \\
\hline \multirow{5}{*}{$\begin{array}{c}\text { SWNT-5-5-10 } \\
\mathrm{H}_{2} \mathrm{O}-\mathrm{in}\end{array}$} & O----C1 & 0.008 & -0.008 & -0.001 \\
\hline & O----C3 & 0.005 & -0.005 & -0.001 \\
\hline & H1----C2 & 0.008 & -0.008 & -0.002 \\
\hline & H1----C4 & 0.007 & -0.007 & -0.001 \\
\hline & H2----C5 & 0.005 & -0.005 & -0.001 \\
\hline \multirow{2}{*}{$\begin{array}{c}\text { SWNT-5-5-10 } \\
\mathrm{H}_{2} \mathrm{O} \text {-out }\end{array}$} & $\mathrm{O}----\mathrm{C} 1$ & 0.009 & -0.007 & -0.001 \\
\hline & O----C2 & 0.004 & -0.004 & -0.001 \\
\hline
\end{tabular}




\begin{tabular}{|c|c|c|c|c|}
\hline Host-guest complexes & BCP & $\rho(\mathbf{r})$ & $\nabla^{2} \rho(\mathbf{r})$ & $H(\mathbf{r})$ \\
\hline & H1----C3 & 0.002 & -0.001 & -0.001 \\
\hline & H1----C4 & 0.002 & -0.001 & -0.001 \\
\hline \multirow{4}{*}{$\begin{array}{c}\text { DWNT-3-3-8 } \\
\mathrm{H}_{2} \mathrm{O} \text {-in }\end{array}$} & O----C3 & 0.082 & -0.098 & -0.012 \\
\hline & O----C4 & 0.075 & -0.092 & -0.008 \\
\hline & H1----C1 & 0.145 & -0.050 & -0.076 \\
\hline & $\mathrm{H} 2----\mathrm{C} 2$ & 0.111 & -0.050 & -0.048 \\
\hline \multirow{3}{*}{$\begin{array}{c}\text { DWNT-3-3-8 } \\
\mathrm{H}_{2} \mathrm{O} \text {-out }\end{array}$} & $\mathrm{O}----\mathrm{C} 1$ & 0.014 & -0.013 & -0.001 \\
\hline & O----C2 & 0.015 & -0.015 & -0.002 \\
\hline & O----C3 & 0.015 & -0.015 & -0.002 \\
\hline \multirow{4}{*}{$\begin{array}{c}\text { DWNT-5-5-10 } \\
\mathrm{H}_{2} \mathrm{O} \text {-in }\end{array}$} & $\mathrm{O}----\mathrm{C} 2$ & 0.009 & -0.008 & -0.001 \\
\hline & H1----C1 & 0.006 & -0.006 & -0.001 \\
\hline & $\mathrm{H} 2----\mathrm{C} 3$ & 0.008 & -0.008 & -0.001 \\
\hline & $\mathrm{H} 2----\mathrm{C} 4$ & 0.007 & -0.007 & -0.001 \\
\hline \multirow{2}{*}{$\begin{array}{c}\text { DWNT-5-5-10 } \\
\text { H }_{2} \mathrm{O} \text {-out }\end{array}$} & $\mathrm{O}----\mathrm{C} 1$ & 0.007 & -0.003 & -0.001 \\
\hline & O----C2 & 0.006 & -0.003 & -0.001 \\
\hline
\end{tabular}

For example, in SWCNT(N)-3-3-8 and water complex, the values of $\rho(\mathrm{r}), \nabla^{2} \rho(\mathrm{r})$, and $H(\mathrm{r})$ for critical bond point (BCP) of $\mathrm{O}$ and $\mathrm{C} 1$ (O----C1) are 0.104, -0.111, and -0.024 a.u., respectively (Figure 7). The BCPs and ELF maps of other NTs are also depicted (Figure S6). It is worth mentioning that the $\rho(\mathrm{r})$ values for host-guest complexes with waters at tips appear less than those of water inside. For instance, SWCNT(O)-3-3-8- $\mathrm{H}_{2} \mathrm{O}-$ out and SWCNT(O)-3-3$8-\mathrm{H}_{2} \mathrm{O}$-in complexes display $\rho(\mathrm{r})$ values of 0.011 and 0.105 a.u., respectively. In addition, the weakest interactions are attributed to the SWCNTs and water for showing the lowest values of $\rho(\mathrm{r}), \nabla^{2} \rho(\mathrm{r})$, and $H(\mathrm{r})$.
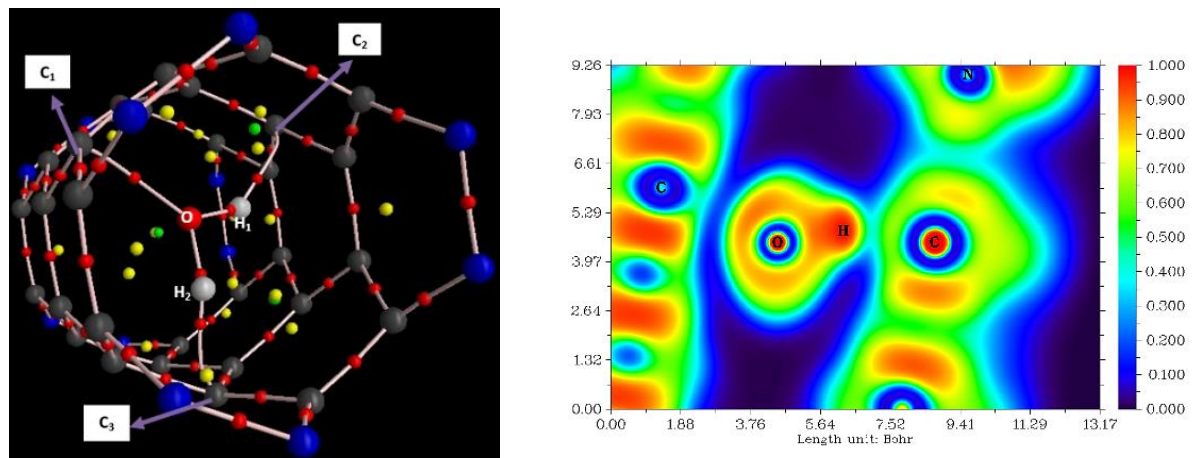

Figure 7. The critical points of SWCNT(N)-3-3-8- $\mathrm{H}_{2} \mathrm{O}-\mathrm{in}$ (left) and its corresponding electron localized function (ELF) map (right). The BCPs are represented by red-colored circles.

\subsection{Natural bond orbital (NBO).}

To further study the nature of the bond, NBO analysis is conducted using second-order perturbation theory. The donor-acceptor interactions with their corresponding energies $\left(E_{2}\right)$ quantitatively show the strength of interactions (Tables S2-S8). This type of interaction may be described as a charge transfer from a Lewis orbital to a non-Lewis orbital. A higher $E_{2}$ implies a stronger interaction. The SWCNT-3-3-8, SWCNT(N)-3-3-8, and SWCNT(O)-3-3-8 show the strongest interactions (Tables 6-8). For example, SWCNT-3-3-8 and water show $E_{2}$ values of 43.98 and $26.73 \mathrm{kcal} / \mathrm{mol}$ for $\pi_{\mathrm{C} 13-\mathrm{C} 14} \rightarrow \mathrm{LP}^{*}{ }_{\mathrm{O} 43}$ and $\pi_{\mathrm{C} 19-\mathrm{C} 21} \rightarrow \mathrm{LP}^{*}{ }_{\mathrm{O} 43}$ interactions, respectively (Table 6).

\section{Conclusions}

In this study, we scrutinized the interaction of water with various types of NTs, including SWCNTs and DWCNTs. All geometries turn out as minima on their energy surfaces. Various structural and thermodynamic parameters such as bond length, bond angle, $E_{\mathrm{int}}, E_{\mathrm{b}}$, 
$\Delta G, E_{\mathrm{g}}$, along with ESP and ELF maps, HOMO-LUMO representations, AIM and NBO analyses, DOS plot, and real space function diagram are calculated.

Table 6. Donor-acceptor interactions ( $\mathrm{kcal} / \mathrm{mol}$ ) of SWCNT-3-3-8 and water.

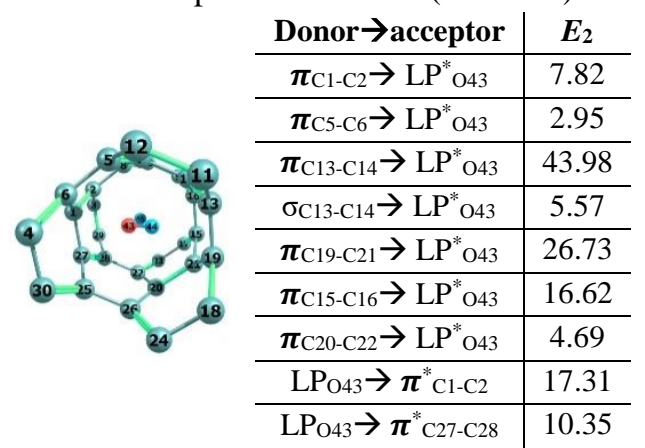

Table 7. Donor-acceptor interactions (kcal/mol) of SWCNT(N)-3-3-8 and water.

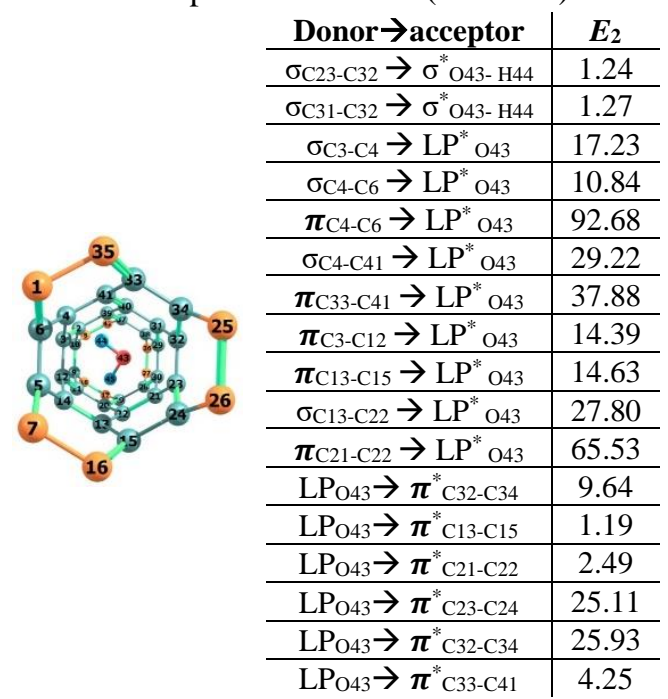

Table 8. Donor-acceptor interactions (kcal/mol) of SWCNT(O)-3-3-8 and water.

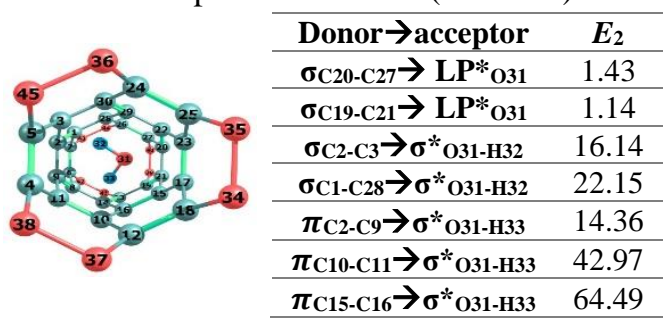

The results indicate that water inside the SWCNTs shows higher interaction with NT where the nature of interactions is partially electrostatic-partially covalent. The SWCNT-3-38, SWCNT(N)-3-3-8, and SWCNT(O)-3-3-8 show the strongest interactions with water and turn out as the best candidates for carrying and storage water molecules.

\section{Funding}

This research was funded by Semnan University.

\section{Acknowledgments}

We gratefully acknowledge Semnan University for financial support. 


\section{Conflicts of Interest}

There is no conflict of interest to declare.

\section{References}

1. Rubio, A.; Corkill, J.L.; Cohen, M.L. Theory of Graphitic Boron Nitride Nanotubes. Physical Review B 1994, 49, 5081, https://doi.org/10.1103/physrevb.49.5081.

2. Wongchoosuk, C.; Krongsuk, S.; Kerdcharoen, T. Theoretical Investigations on the Tip-Functionalised Carbon Nanotubes Interacting with Water. International Journal of Nanoparticles 2008, 1, 136-151, https://doi.org/10.1504/IJNP.2008.020268.

3. Hatta, N.; Murata, K. Very Long Graphitic Nano-Tubules Synthesized by Plasma-Decomposition of Benzene. Chemical physics letters 1994, 217, 393-402, https://doi.org/10.1016/0009-2614(93)E1414-C.

4. Bethune, D.S.; Kiang, C.H.; De Vries, M.S.; Gorman, G.; Savoy, R.; Vazquez, J.; Beyers, R. CobaltCatalysed Growth of Carbon Nanotubes with Single-Atomic-Layer Walls. Nature 1993, 363, 605-607, https://doi.org/10.1038/363605a0.

5. Rao, C.N.R.; Seshadri, R.; Govindaraj, A.; Sen, R. Fullerenes, Nanotubes, Onions and Related Carbon Structures. Materials Science and Engineering: R: Reports 1995, 15, 209-262,. https://doi.org/10.1016/S0927-796X(95)00181-6.

6. Ivanov, V.; Nagy, J.B.; Lambin, P.; Lucas, A.; Zhang, X.B.; Zhang, X.F.; Bernaerts, D.; Van Tendeloo, G.; Amelinckx, S.; Van Landuyt, J. The Study of Carbon Nanotubules Produced by Catalytic Method. Chemical Physics Letters 1994, 223, 329-335, https://doi.org/10.1016/0009-2614(94)00467-6.

7. Rao, C.N.R.; Satishkumar, B.C.; Govindaraj, A.; Nath, M. Nanotubes. ChemPhysChem 2001, 2, 78-105, https://doi.org/10.1002/1439-7641(20010216)2:2<78::AID-CPHC78>3.0.CO;2-7.

8. Saifutdinova, A.A.; Sofronitskiy, A.O.; Timerkaev, B.A.; Saifutdinov, A.I. Plasma-Chemical Decomposition of Hydrocarbons on the Basis of the Micro-Arc Discharge with Disc Electrodes Rotating in the Bulk of Raw Materials. Russian Physics Journal 2020, 1-5, https://doi.org/10.1007/s11182-020-01957-0.

9. Shavelkina, M.B.; Amirov, R.H. Direct Synthesis of Hydrogenated Graphene via Hydrocarbon Decomposition in Plasmas. Наносистемы: физика, химия, математика 2019, 10, 102-106, https://doi.org/10.17586/2220-8054-2019-10-1-102-106.

10. Rudneva, Y.V; Shubin, Y.V; Plyusnin, P.E.; Bauman, Y.I.; Mishakov, I.V; Korenev, S.V; Vedyagin, A.A. Preparation of Highly Dispersed Ni1-XPdx Alloys for the Decomposition of Chlorinated Hydrocarbons. Journal of Alloys and Compounds 2019, 782, 716-722, https://doi.org/10.1016/j.jallcom.2018.12.207.

11. Xin, L.; Liu, C.; Liu, Y.; Huo, E.; Li, Q.; Wang, X.; Cheng, Q. Thermal Decomposition Mechanism of Some Hydrocarbons by ReaxFF-Based Molecular Dynamics and Density Functional Theory Study. Fuel 2020, 275, 117885, https://doi.org/10.1016/j.fuel.2020.117885.

12. Hidalgo, P.; Navia, R.; Hunter, R.; Coronado, G.; Gonzalez, M. Synthesis of Carbon Nanotubes Using Biochar as Precursor Material under Microwave Irradiation. Journal of environmental management 2019, 244, 83-91, https://doi.org/10.1016/j.jenvman.2019.03.082.

13. Cheung, K.Y.; Watanabe, K.; Segawa, Y.; Itami, K. Synthesis of a Zigzag Carbon Nanobelt. Nature Chemistry 2021, 13, 255-259, https://doi.org/10.1038/s41557-020-00627-5.

14. Rahman, G.; Najaf, Z.; Mehmood, A.; Bilal, S.; Mian, S.A.; Ali, G. An Overview of the Recent Progress in the Synthesis and Applications of Carbon Nanotubes. C-Journal of Carbon Research 2019, 5, 3, https://doi.org/10.3390/c5010003.

15. Gupta, N.; Gupta, S.M.; Sharma, S.K. Carbon Nanotubes: Synthesis, Properties and Engineering Applications. Carbon Letters 2019, 29, 419-447, https://doi.org/10.1007/s42823-019-00068-2.

16. Yue, Z.; Gao, T.; Li, H. Robust Synthesis of Carbon@Na4Ti9O20 Core-Shell Nanotubes for Hybrid Capacitive Deionization with Enhanced Performance. Desalination 2019, 449, 69-77, https://doi.org/10.1016/j.desal.2018.10.018.

17. Dai, H. Carbon Nanotubes: Opportunities and Challenges. Surface Science 2002, 500, 218-241, https://doi.org/10.1016/S0039-6028(01)01558-8.

18. Terrones, M. Science and Technology of the Twenty-First Century: Synthesis, Properties, and Applications of Carbon Nanotubes. Annual review of materials research 2003, 33, 419-501, https://doi.org/10.1146/annurev.matsci.33.012802.100255.

19. Roux, B.; Karplus, M. Molecular Dynamics Simulations of the Gramicidin Channel. Annual review of $\begin{array}{lllll}\text { biophysics and biomolecular } & \text { structure } & \mathbf{1 9 9 4 ,} & 23, & 731-761 \text {, }\end{array}$ https://doi.org/10.1146/annurev.bb.23.060194.003503.

20. Fu, D.; Libson, A.; Miercke, L.J.W.; Weitzman, C.; Nollert, P.; Krucinski, J.; Stroud, R.M. Structure of a Glycerol-Conducting Channel and the Basis for Its Selectivity. Science 2000, 290, 481-486, https://doi.org/10.1126/science.290.5491.481.

21. Journet, C.; Maser, W.K.; Bernier, P.; Loiseau, A.; de La Chapelle, M.L.; Lefrant, dl S.; Deniard, P.; Lee, R.; Fischer, J.E. Large-Scale Production of Single-Walled Carbon Nanotubes by the Electric-Arc Technique. nature 1997, 388, 756-758, https://doi.org/10.1038/41972.

https://biointerfaceresearch.com/ 
22. Zhang, J.; Cui, J.; Wei, F.; Wang, W.; He, X.; Mei, X. Investigating Limiting Factors for Self-Assembly of Carbon Nanotubes: A Molecular Dynamics Simulation Study. Applied Surface Science 2020, 504, 144397, https://doi.org/10.1016/j.apsusc.2019.144397.

23. Lapano, J.; Dyck, O.; Lupini, A.; Ko, W.; Li, H.; Miao, H.; Lee, H.N.; Li, A.-P.; Brahlek, M.; Jesse, S. Van Der Waals Epitaxy on Freestanding Monolayer Graphene Membrane by MBE. arXiv preprint arXiv:2103.15905 2021.

24. Scrivens, W.A.; Tour, J.M. Potent Solvents for $\mathrm{C}_{60}$ and Their Utility for the Rapid Acquisition of ${ }^{13} \mathrm{C}$ NMR Data for Fullerenes. J. Chem. Soc., Chem. Commun., 1993, 1207-1209, https://doi.org/10.1039/C39930001207.

25. Ruoff, R.S.; Tse, D.S.; Malhotra, R.; Lorents, D.C. Solubility of Fullerene (C60) in a Variety of Solvents. The Journal of Physical Chemistry 1993, 97, 3379-3383, https://doi.org/10.1021/j100115a049.

26. Gazia, M.A.; El-Magd, M.A. Effect of Pristine and Functionalized Multiwalled Carbon Nanotubes on Rat Renal Cortex. Acta histochemica 2019, 121, 207-217, https://doi.org/10.1016/j.acthis.2018.12.005.

27. Dinesh, B.; Shalini Devi, K.S.; Krishnan, U.M. Achieving a Stable High Surface Excess of Glucose Oxidase on Pristine Multiwalled Carbon Nanotubes for Glucose Quantification. ACS Applied Bio Materials 2019, 2 , 1740-1750, https://doi.org/10.1021/acsabm.9b00145.

28. Di Giosia, M.; Marforio, T.D.; Cantelli, A.; Valle, F.; Zerbetto, F.; Su, Q.; Wang, H.; Calvaresi, M. Inhibition of $\alpha$-Chymotrypsin by Pristine Single-Wall Carbon Nanotubes: Clogging up the Active Site. Journal of colloid and interface science 2020, 571, 174-184, https://doi.org/10.1016/j.jcis.2020.03.034.

29. da Luz, G.; Gleize, P.J.P.; Batiston, E.R.; Pelisser, F. Effect of Pristine and Functionalized Carbon Nanotubes on Microstructural, Rheological, and Mechanical Behaviors of Metakaolin-Based Geopolymer. Cement and Concrete Composites 2019, 104, 103332, https://doi.org/10.1016/j.cemconcomp.2019.05.015.

30. Silva, M.A.; Hilliou, L.; de Amorim, M.T.P. Fabrication of Pristine-Multiwalled Carbon Nanotubes/Cellulose Acetate Composites for Removal of Methylene Blue. Polymer Bulletin 2020, 77, 623-653, https://doi.org/10.1007/s00289-019-02769-0.

31. Breitwieser, A.; Sleytr, U.B.; Pum, D. A New Method for Dispersing Pristine Carbon Nanotubes Using Regularly Arranged S-Layer Proteins. Nanomaterials 2021, 11, 1346, https://doi.org/10.3390/nano11051346.

32. Huang, J.-E.; Li, X.-H.; Xu, J.-C.; Li, H.-L. Well-Dispersed Single-Walled Carbon Nanotube/Polyaniline Composite Films. Carbon 2003, 41, 2731-2736, https://doi.org/10.1016/S0008-6223(03)00359-2.

33. Tasis, D.; Tagmatarchis, N.; Georgakilas, V.; Prato, M. Soluble Carbon Nanotubes. Chemistry-A European Journal 2003, 9, 4000-4008, https://doi.org/10.1002/chem.200304800.

34. Riggs, J.E.; Guo, Z.; Carroll, D.L.; Sun, Y.-P. Strong Luminescence of Solubilized Carbon Nanotubes. Journal of the American Chemical Society 2000, 122, 5879-5880, https://doi.org/10.1021/ja9942282.

35. Pinto, A.V; Magalhães, A.L. Intramolecular Hydrogen Bonds in Tip-Functionalized Single-Walled Carbon Nanotubes as PH-Sensitive Gates. The Journal of Physical Chemistry A 2020, 124, 9542-9551, https://doi.org/10.1021/acs.jpca.0c03710.

36. Hong, Y.; Zhang, J.; Zhu, C.; Zeng, X.C.; Francisco, J. S. Water Desalination through Rim Functionalized Carbon Nanotubes. Journal of Materials Chemistry A 2019, 7, 3583-3591, https://doi.org/10.1039/C8TA10941A.

37. Ali, S.; Rehman, S.A.U.; Luan, H.-Y.; Farid, M.U.; Huang, H. Challenges and Opportunities in Functional Carbon Nanotubes for Membrane-Based Water Treatment and Desalination. Science of the Total Environment 2019, 646, 1126-1139, https://doi.org/10.1016/j.scitotenv.2018.07.348.

38. Panczyk, T.; Wojton, P.; Wolski, P. Molecular Dynamics Study of the Interaction of Carbon Nanotubes with Telomeric DNA Fragment Containing Noncanonical G-Quadruplex and i-Motif Forms. International journal of molecular sciences 2020, 21, 1925, https://doi.org/10.3390/ijms21061925.

39. Díez-Pascual, A.M. Chemical Functionalization of Carbon Nanotubes with Polymers: A Brief Overview. Macromol 2021, 1, 64-83, https://doi.org/10.3390/macromol1020006.

40. Lu, D.; Li, Y.; Ravaioli, U.; Schulten, K. Empirical Nanotube Model for Biological Applications. The Journal of Physical Chemistry B 2005, 109, 11461-11467, https://doi.org/10.1021/jp050420g.

41. Izadi, R.; Tuna, M.; Trovalusci, P.; Ghavanloo, E. Torsional Characteristics of Carbon Nanotubes: Micropolar Elasticity Models and Molecular Dynamics Simulation. Nanomaterials 2021, 11, 453, https://doi.org/10.3390/nano11020453.

42. Cui, J.; Ren, X.; Mei, H.; Wang, X.; Zhang, J.; Fan, Z.; Wang, W.; Tohmyoh, H.; Mei, X. Molecular Dynamics Simulation Study on the Interfacial Contact Behavior between Single-Walled Carbon Nanotubes and Nanowires. Applied Surface Science 2020, 512, 145696, https://doi.org/10.1016/j.apsusc.2020.145696.

43. Patmanidis, I.; de Vries, A.H.; Wassenaar, T.A.; Wang, W.; Portale, G.; Marrink, S.J. Structural Characterization of Supramolecular Hollow Nanotubes with Atomistic Simulations and SAXS. Physical Chemistry Chemical Physics 2020, 22, 21083-21093, https://doi.org/10.1039/D0CP03282D.

44. Hummer, G.; Rasaiah, J.C.; Noworyta, J.P. Water Conduction through the Hydrophobic Channel of a Carbon Nanotube. Nature 2001, 414, 188-190, https://doi.org/10.1038/35102535.

45. Mashl, R.J.; Joseph, S.; Aluru, N.R.; Jakobsson, E. Anomalously Immobilized Water: A New Water Phase Induced by Confinement in Nanotubes. Nano letters 2003, 3, 589-592, https://doi.org/10.1021/nl0340226.

46. Zhu, F.; Schulten, K. Water and Proton Conduction through Carbon Nanotubes as Models for Biological 
Channels. Biophysical journal 2003, 85, 236-244, https://doi.org/10.1016/S0006-3495(03)74469-5.

47. Zheng, J.; Lennon, E.M.; Tsao, H.-K.; Sheng, Y.-J.; Jiang, S. Transport of a Liquid Water and Methanol Mixture through Carbon Nanotubes under a Chemical Potential Gradient. The Journal of chemical physics 2005, 122, 214702, https://doi.org/10.1063/1.1908619.

48. Afchangi, L.; Fazli, M. Investigation of the Nanotubes-H2O Complex by Molecular Mechanics and Semi Empirical Methods. BIOINTERFACE RESEARCH IN APPLIED CHEMISTRY 2018, 8, 3700-3704.

49. Zhang, J.; Zou, H.; Qing, Q.; Yang, Y.; Li, Q.; Liu, Z.; Guo, X.; Du, Z. Effect of Chemical Oxidation on the Structure of Single-Walled Carbon Nanotubes. The Journal of Physical Chemistry B 2003, 107, 3712-3718, https://doi.org/10.1021/jp027500u.

50. Itkis, M.E.; Niyogi, S.; Meng, M.E.; Hamon, M.A.; Hu, H.; Haddon, R.C. Spectroscopic Study of the Fermi Level Electronic Structure of Single-Walled Carbon Nanotubes. Nano Letters 2002, 2, 155-159, https://doi.org/10.1021/n10156639.

51. Kavan, L.; Rapta, P.; Dunsch, L.; Bronikowski, M.J.; Willis, P.; Smalley, R.E. Electrochemical Tuning of Electronic Structure of Single-Walled Carbon Nanotubes: In-Situ Raman and Vis-NIR Study. The Journal of Physical Chemistry B 2001, 105, 10764-10771, https://doi.org/10.1021/jp011709a.

52. Hamon, M.A.; Itkis, M.E.; Niyogi, S.; Alvaraez, T.; Kuper, C.; Menon, M.; Haddon, R.C. Effect of Rehybridization on the Electronic Structure of Single-Walled Carbon Nanotubes. Journal of the American Chemical Society 2001, 123, 11292-11293, https://doi.org/10.1021/ja0109702.

53. Gojny, F.H.; Nastalczyk, J.; Roslaniec, Z.; Schulte, K. Surface Modified Multi-Walled Carbon Nanotubes in CNT/Epoxy-Composites. Chemical physics letters 2003, 370, 820-824, https://doi.org/10.1016/S00092614(03)00187-8.

54. Yu, M.-F.; Lourie, O.; Dyer, M.J.; Moloni, K.; Kelly, T.F.; Ruoff, R.S. Strength and Breaking Mechanism of Multiwalled Carbon Nanotubes under Tensile Load. Science 2000, 287, 637-640, https://doi.org/10.1126/science.287.5453.637.

55. Behler, K.; Osswald, S.; Ye, H.; Dimovski, S.; Gogotsi, Y. Effect of Thermal Treatment on the Structure of Multi-Walled Carbon Nanotubes. Journal of Nanoparticle Research 2006, 8, 615-625, https://doi.org/10.1007/s11051-006-9113-6.

56. Wepasnick, K.A.; Smith, B.A.; Schrote, K.E.; Wilson, H.K.; Diegelmann, S.R.; Fairbrother, D.H. Surface and Structural Characterization of Multi-Walled Carbon Nanotubes Following Different Oxidative Treatments. Carbon 2011, 49, 24-36, https://doi.org/10.1016/j.carbon.2010.08.034.

57. Chen, Z.; Nagase, S.; Hirsch, A.; Haddon, R.C.; Thiel, W.; Schleyer, P. von R. Side-Wall Opening of SingleWalled Carbon Nanotubes (SWCNTs) by Chemical Modification: A Critical Theoretical Study. Angewandte Chemie 2004, 116, 1578-1580, https://doi.org/10.1002/anie.200353087.

58. Kruse, H.; Grimme, S.A Geometrical Correction for the Inter-and Intra-Molecular Basis Set Superposition Error in Hartree-Fock and Density Functional Theory Calculations for Large Systems. The Journal of chemical physics 2012, 136, 04B613, https://doi.org/10.1063/1.3700154.

59. Boys, S.F.; Bernardi, F. The Calculation of Small Molecular Interactions by the Differences of Separate Total Energies. Some Procedures with Reduced Errors. Molecular Physics 1970, 19, 553-566, https://doi.org/10.1080/00268977000101561.

60. Umadevi, D.; Sastry, G.N. Quantum Mechanical Study of Physisorption of Nucleobases on Carbon Materials: Graphene versus Carbon Nanotubes. The Journal of Physical Chemistry Letters 2011, 2, 1572-1576, https://doi.org/10.1021/jz200705w.

61. Juárez, A.R.; Ortíz-Chi, F.; Pino-Ríos, R.; Cárdenas-Jirón, G.; Villanueva, M.S.; Anota, E.C. The Boron Nitride (B116N124) Fullerene: Stability and Electronic Properties from DFT Simulations. Chemical Physics Letters 2020, 741, 137097, https://doi.org/10.1016/j.cplett.2020.137097.

62. Karjabad, K.D.; Mohajeri, S.; Shamel, A.; Khodadadi-Moghaddam, M.; Rajaei, G.E. Boron Nitride Nanoclusters as a Sensor for Cyclosarin Nerve Agent: DFT and Thermodynamics Studies. SN Applied Sciences 2020, 2, 1-8, https://doi.org/10.1007/s42452-020-2411-2.

63. Bahrami, A.; Seidi, S.; Baheri, T.; Aghamohammadi, M.A First-Principles Study on the Adsorption Behavior of Amphetamine on Pristine, P-and Al-Doped B12N12 Nano-Cages. Superlattices and Microstructures 2013, 64, 265-273, https://doi.org/10.1016/j.spmi.2013.09.034.

64. Glendening, E.D.; Landis, C.R.; Weinhold, F. Natural Bond Orbital Methods. Wiley interdisciplinary reviews: computational molecular science 2012, 2, 1-42, https://doi.org/10.1002/wcms.51.

65. Kumar, P.S.V.; Raghavendra, V.; Subramanian, V. Bader's Theory of Atoms in Molecules (AIM) and Its Applications to Chemical Bonding. Journal of Chemical Sciences 2016, 128, 1527-1536, https://doi.org/10.1007/s12039-016-1172-3. 


\section{Supplementary Information}
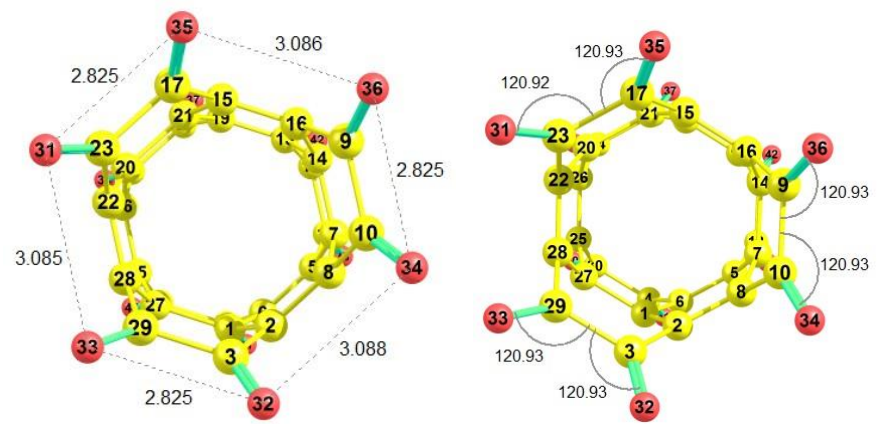

Figure S1. Structural parameters of the tip of SWCNT(O)-3-3-8 including bond lengths and bond angles.

HOMO

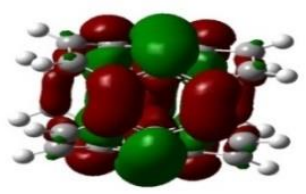

LUMO
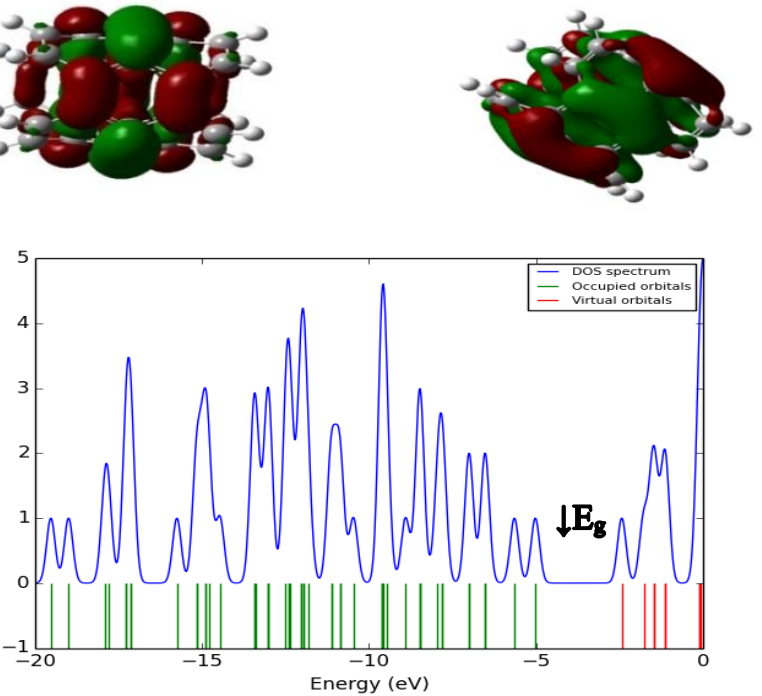

Figure S2. The DOS plot and HOMO-LUMO representation of SWCNT-3-3-8 with water inside.

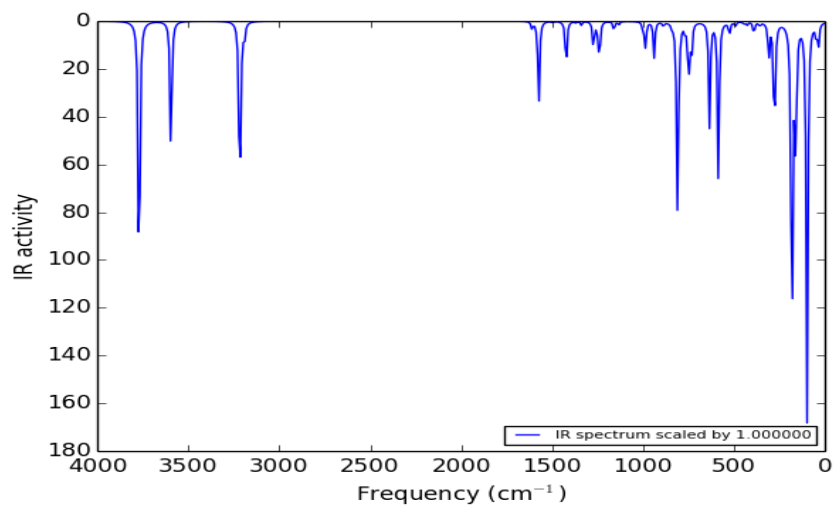

Figure S3. The IR spectrum of SWCNT-3-3-8. 


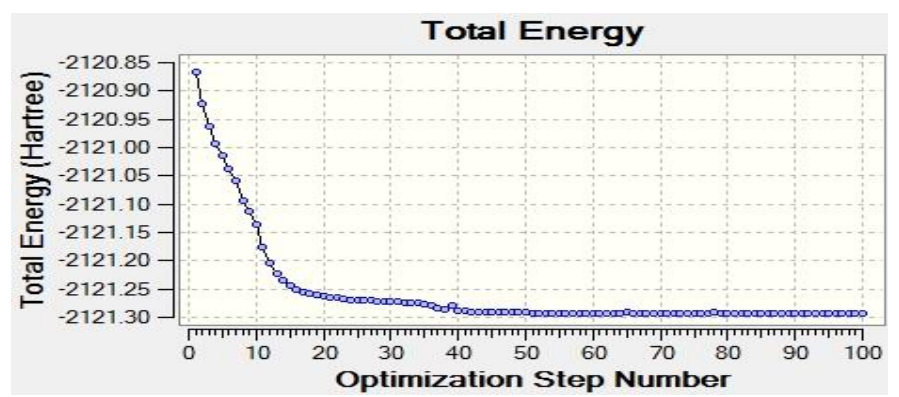

Figure S4. Optimization steps and total energy of $\mathrm{H}_{2} \mathrm{O}$ and SWCNT-3-3-8.
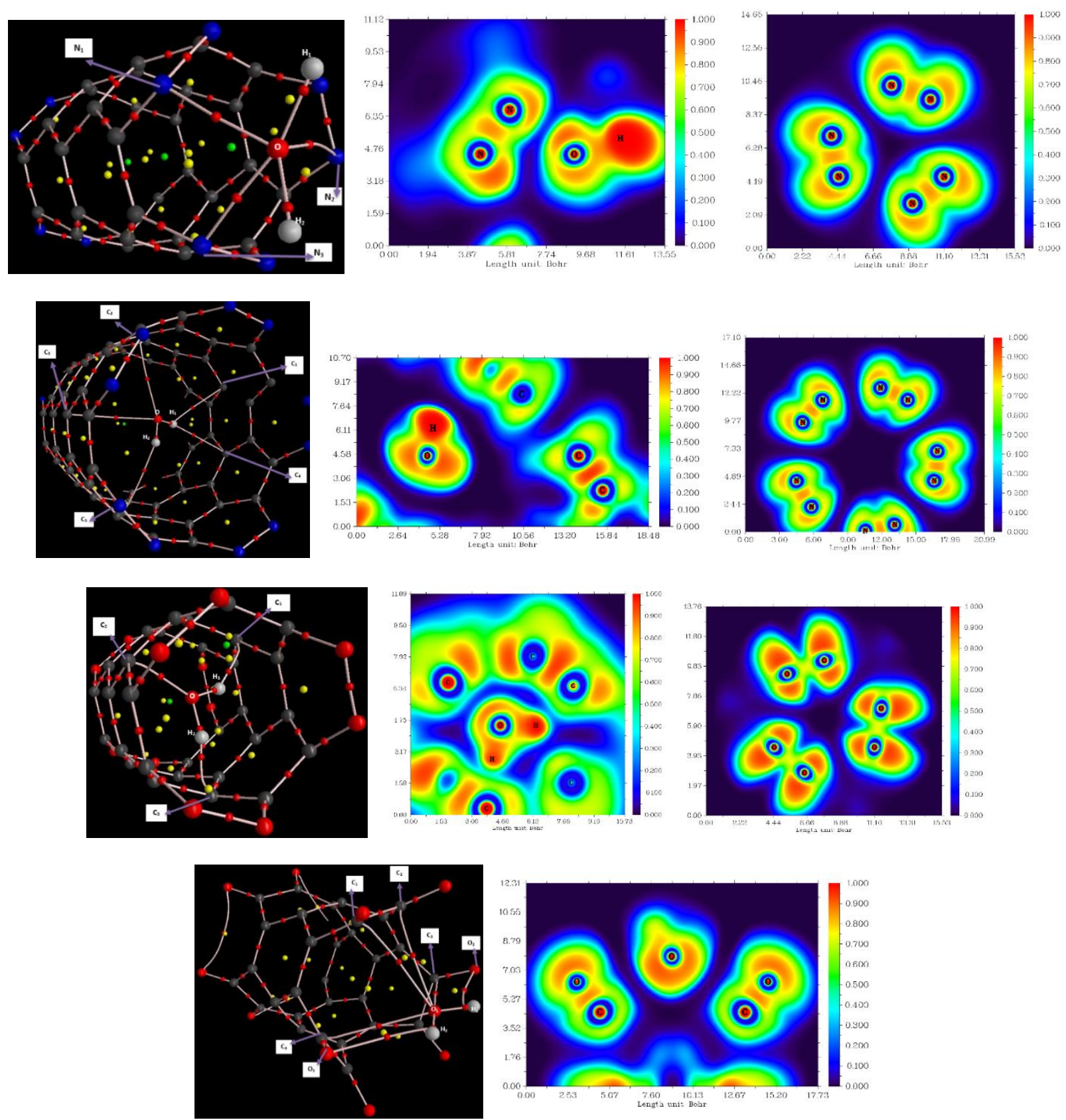

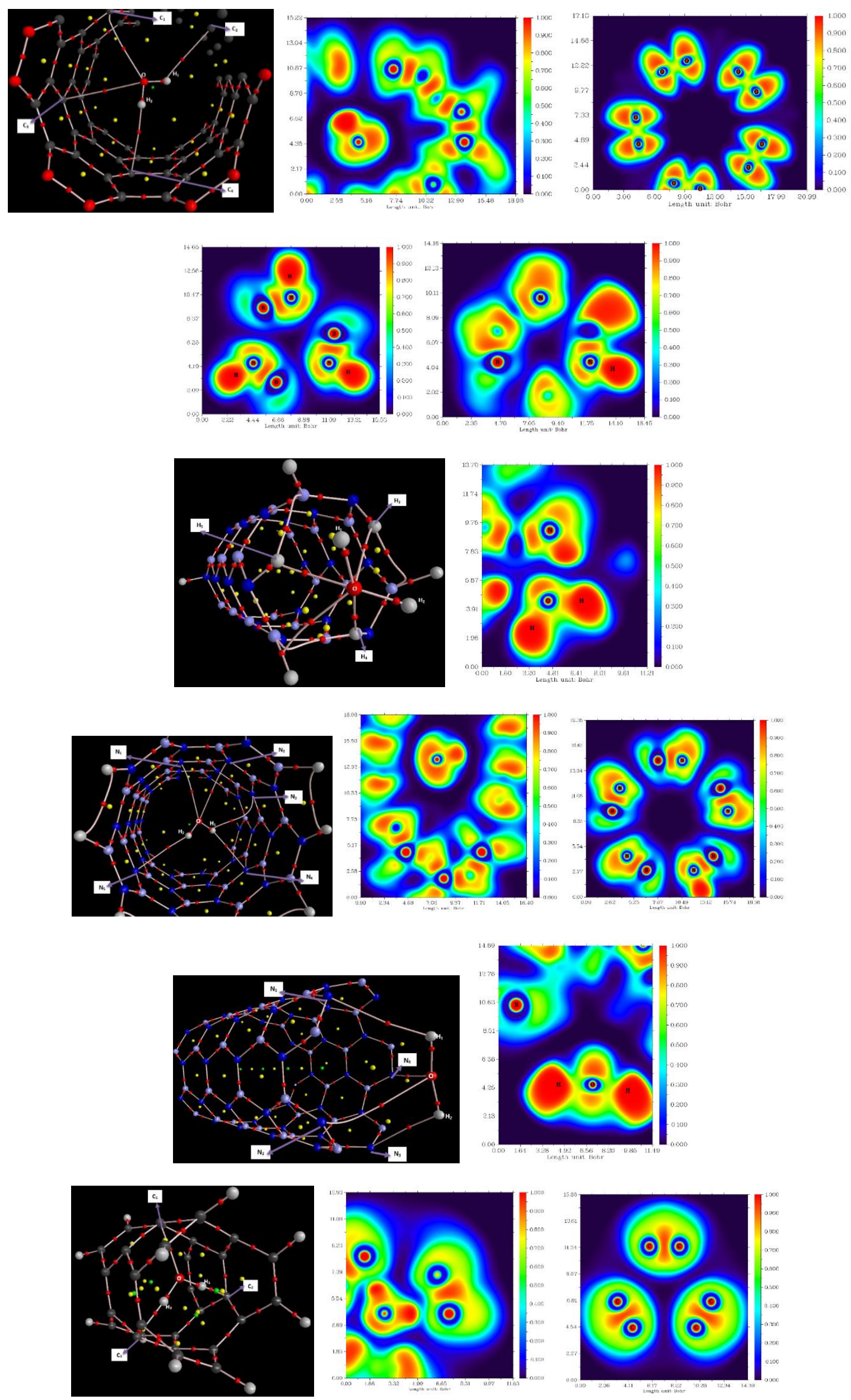

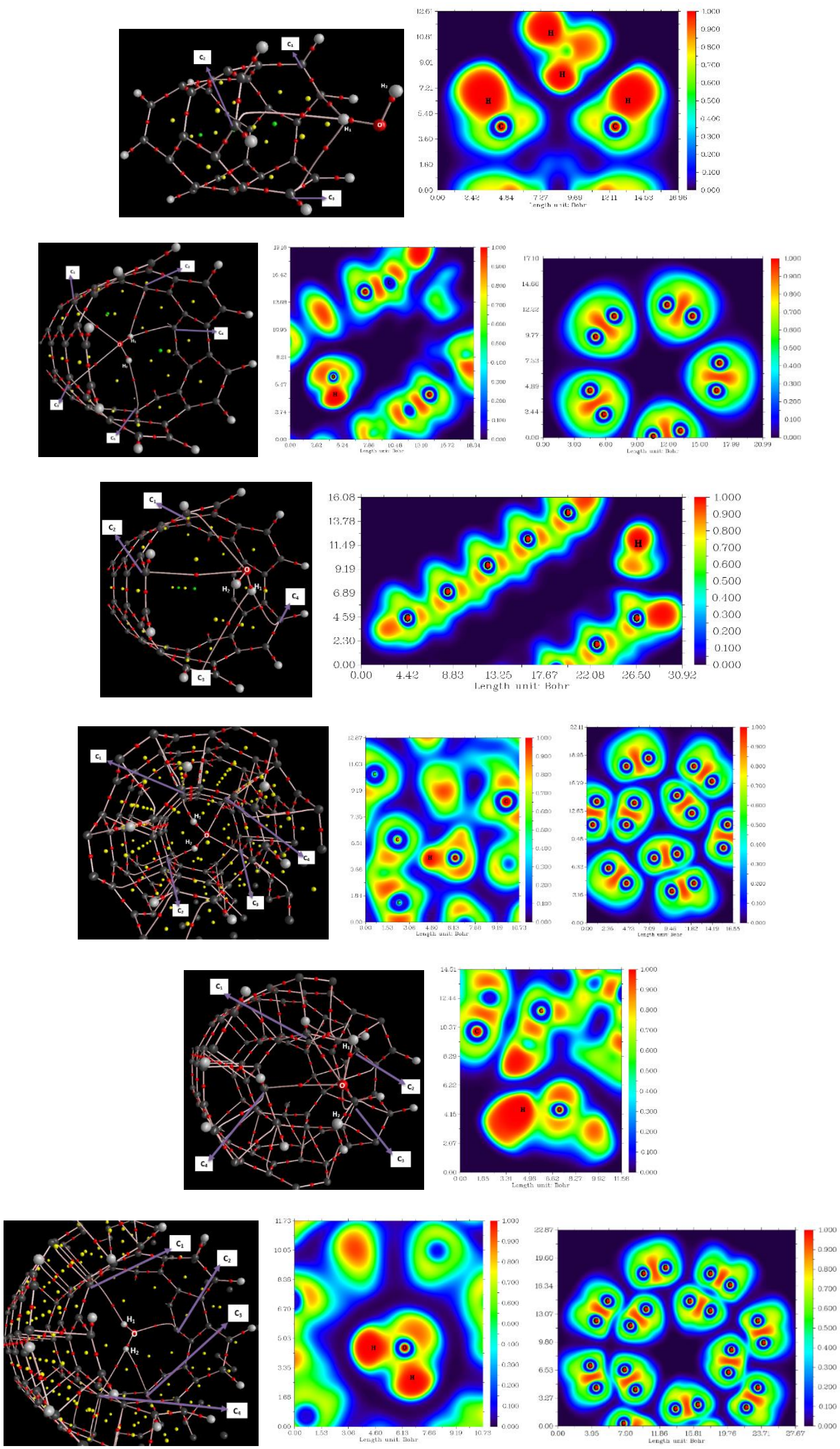

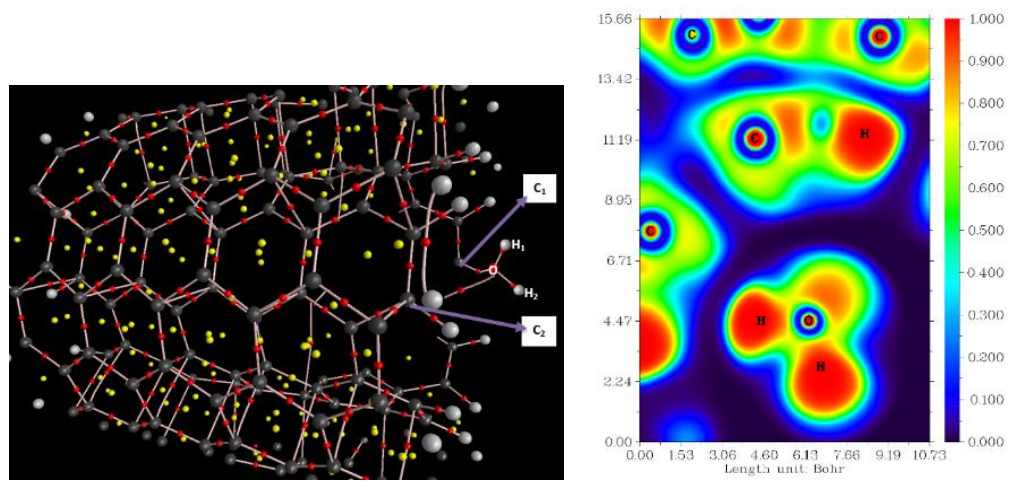

Figure S5. The calculated BCPs and ELF maps of NTs.
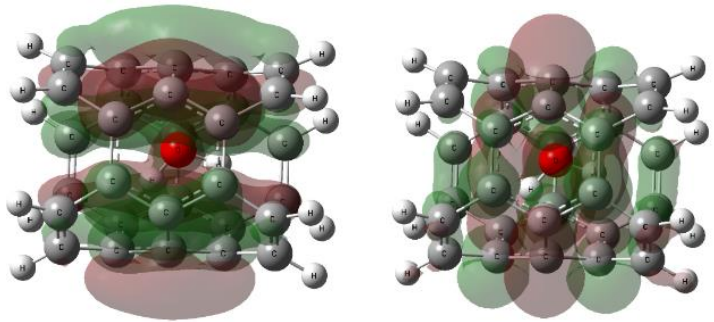

Figure S6. The HOMO-LUMO representations of SWCNT-3-3-8- $\mathrm{H}_{2} \mathrm{O}-\mathrm{in}$.
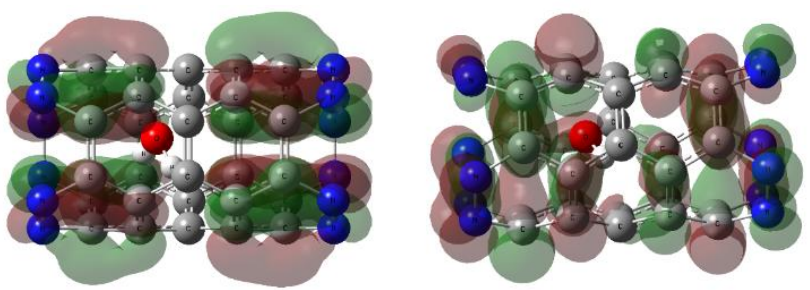

Figure S7. The HOMO-LUMO representations of SWCNT(N)-3-3-8- $\mathrm{H}_{2} \mathrm{O}-\mathrm{in}$.
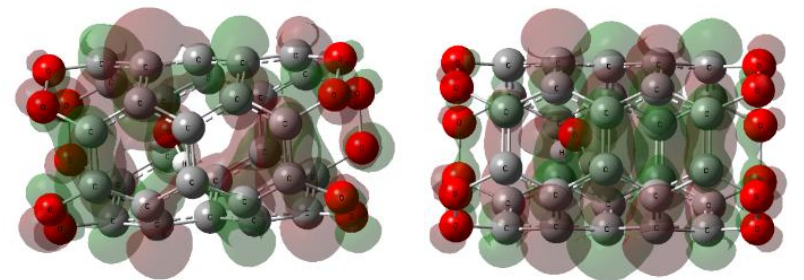

Figure S8. The HOMO-LUMO representations of SWCNT(O)-3-3-8- $\mathrm{H}_{2} \mathrm{O}$-in.

Table S1. Thermodynamic parameters of SWNT-3-3-8 and SWNT-3-3-8- $\mathrm{H}_{2} \mathrm{O}-\mathrm{in}$.

\begin{tabular}{c|c|c} 
Structure & SWNT-3-3-8 & SWNT-3-3-8-H H $_{2} \mathbf{O}$-in \\
\hline $\mathrm{E}_{\text {zpe }}$ & 0.328445 & 0.33993 \\
\hline $\mathrm{E}_{\text {tot }}$ & -1149.86 & -1226.20 \\
\hline $\mathrm{H}_{\text {corr }}$ & 0.329389 & 0.356927 \\
\hline $\mathrm{G}_{\text {corr }}$ & 0.271897 & 0.300302 \\
\hline$\mu /$ Debye & 0.0012 & 2.1405 \\
\hline$\varepsilon_{\mathrm{o}}+\mathrm{E}_{\text {zpe }}$ & -1149.55 & -1225.62 \\
\hline$\varepsilon_{\mathrm{o}}+\mathrm{H}_{\text {corr }}$ & -1149.53 & -1225.6 \\
\hline$\varepsilon_{\mathrm{o}}+\mathrm{G}_{\text {corr }}$ & -1149.59 & -1225.66
\end{tabular}


Table S2. Donor-acceptor interactions of SWCNT(N)-5-5-10- $\mathrm{H}_{2} \mathrm{O}-\mathrm{in}$.

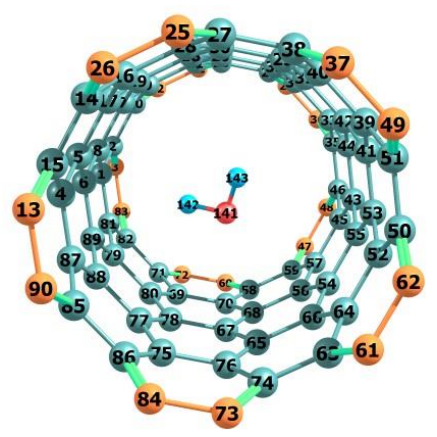

\begin{tabular}{c|c} 
Donor $\rightarrow$ acceptor & $\boldsymbol{E}_{2}$ \\
\hline$\sigma_{\mathrm{O} 141-\mathrm{H} 142} \rightarrow \sigma^{*} \mathrm{C} 5-\mathrm{H} 93$ & 0.11 \\
\hline$\sigma_{\mathrm{O} 141-\mathrm{H} 142} \rightarrow \sigma^{*} \mathrm{C} 88-\mathrm{H} 139$ & 0.16 \\
\hline $\mathrm{LP}_{\mathrm{O} 141} \rightarrow \sigma^{*} \mathrm{C} 65-\mathrm{H} 125$ & 0.41 \\
\hline $\mathrm{LP}_{\mathrm{O} 141} \rightarrow \sigma^{*} \mathrm{C} 66-\mathrm{H} 126$ & 0.35 \\
\hline $\mathrm{LP}_{\mathrm{O} 141} \rightarrow \sigma^{*} \mathrm{C} 77-\mathrm{H} 133$ & 0.11
\end{tabular}

Table S3. Donor-acceptor interactions of SWCNT(N)-5-5-10- $\mathrm{H}_{2} \mathrm{O}-$ out.

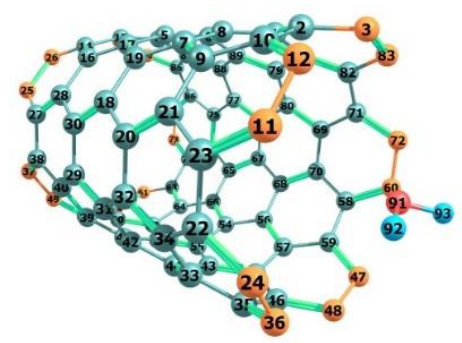

\begin{tabular}{c|c} 
Donor $\rightarrow$ acceptor & $\boldsymbol{E}_{\mathbf{2}}$ \\
\hline $\mathrm{LP}_{\mathrm{N} 24} \rightarrow \sigma^{*}{ }_{\mathrm{O}} \mathrm{O} 1-\mathrm{H} 92$ & 0.85 \\
\hline $\mathrm{LP}_{\mathrm{N} 60} \rightarrow \mathrm{LP}^{*}{ }_{\mathrm{O} 91}$ & 0.16 \\
\hline$\sigma_{\mathrm{O} 91-\mathrm{H} 92} \rightarrow \mathrm{LP}^{*}{ }_{\mathrm{N} 24}$ & 0.58
\end{tabular}

Table S4. Donor-acceptor interactions of SWCNT(N)-3-3-8- $\mathrm{H}_{2} \mathrm{O}-$ out.

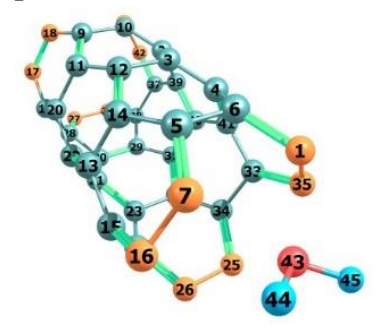

\begin{tabular}{|c|c|}
\hline Donor $\rightarrow$ acceptor & $E_{2}$ \\
\hline $\boldsymbol{\pi}_{\mathrm{C} 5-\mathrm{N} 7} \rightarrow \sigma^{*}{ }_{\mathrm{O} 43-\mathrm{H} 45}$ & 3.22 \\
\hline $\mathrm{LP}_{\mathrm{N} 7} \rightarrow \sigma^{*}{ }_{\mathrm{O} 43-\mathrm{H} 45}$ & 5.90 \\
\hline $\mathrm{LP}_{\mathrm{N} 35} \rightarrow \sigma^{*} \mathrm{O} 43-\mathrm{H} 45$ & 3.59 \\
\hline $\boldsymbol{\pi}_{\mathrm{C} 5-\mathrm{N} 7} \rightarrow \mathrm{LP}^{*}{ }_{\mathrm{O} 43}$ & 1.89 \\
\hline $\mathrm{LP}_{\mathrm{N} 7} \rightarrow \mathrm{LP}^{*}{ }_{\mathrm{O} 43}$ & 20.70 \\
\hline $\mathrm{LP}_{\mathrm{N} 16} \rightarrow \mathrm{LP}^{*}{ }_{\mathrm{O} 43}$ & 1.39 \\
\hline$\sigma_{\mathrm{O} 43-\mathrm{H} 45} \rightarrow \mathrm{LP}_{\mathrm{N} 7}^{*}$ & 1.00 \\
\hline$\sigma_{\mathrm{O} 43-\mathrm{H} 45} \rightarrow \boldsymbol{\pi}^{*}{ }_{\mathrm{C} 5-\mathrm{N} 7}$ & 2.64 \\
\hline $\mathrm{LP}_{\mathrm{O} 43} \rightarrow \boldsymbol{\pi}^{*}{ }_{\mathrm{C} 5-\mathrm{N} 7}$ & 4.82 \\
\hline $\mathrm{LP}_{\mathrm{O} 43} \rightarrow \boldsymbol{\pi}^{*}{ }_{\mathrm{N} 1-\mathrm{N} 35}$ & 10.10 \\
\hline $\mathrm{LP}_{\mathrm{O} 43} \rightarrow \pi^{*}{ }_{\mathrm{C} 5-\mathrm{N} 7}$ & 3.72 \\
\hline
\end{tabular}


Table S5. Donor-acceptor interactions of SWCNT(O)-5-5-10- $\mathrm{H}_{2} \mathrm{O}-\mathrm{in}$.

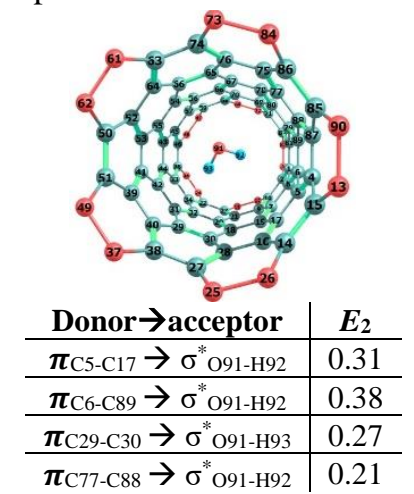

Table S6. Donor-acceptor interactions of SWCNT(O)-5-5-10- $\mathrm{H}_{2} \mathrm{O}-$ out.

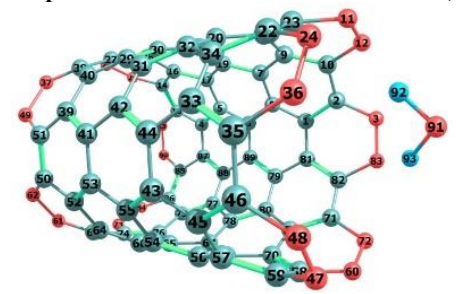

\begin{tabular}{|c|c|}
\hline Donor $\rightarrow$ acceptor & $\boldsymbol{E}_{2}$ \\
\hline $\mathrm{LP}_{\mathrm{O} 11} \rightarrow \sigma^{*}{ }_{\mathrm{O} 91-\mathrm{H} 92}$ & 0.49 \\
\hline $\mathrm{LP}_{\mathrm{O} 24} \rightarrow \sigma^{*} \mathrm{O} 91-\mathrm{H} 92$ & 1.48 \\
\hline $\mathrm{LP}_{\mathrm{O} 83} \rightarrow \sigma^{*} \mathrm{O} 91-\mathrm{H} 93$ & 0.51 \\
\hline$\sigma \mathrm{O} 91-\mathrm{H} 92 \rightarrow \sigma^{*} 22-\mathrm{O} 24$ & 0.08 \\
\hline
\end{tabular}

Table S7. Donor-acceptor interactions of BNNT-3-3-8- $\mathrm{H}_{2} \mathrm{O}-\mathrm{in}$.

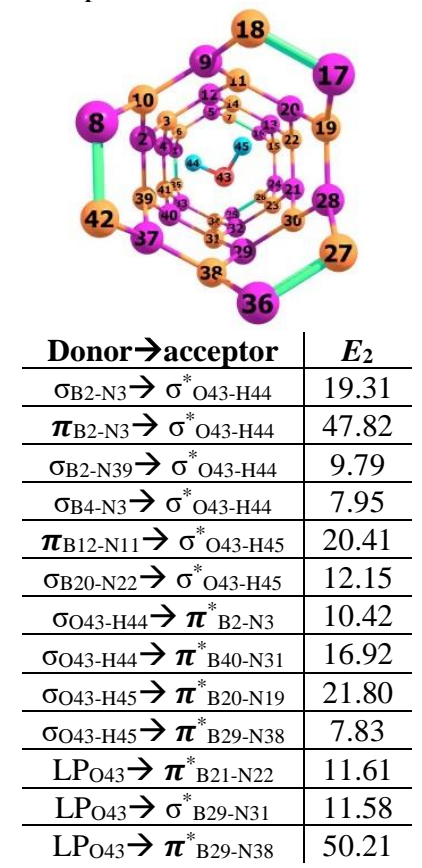

Table S8. Donor-acceptor interactions of BNNT-3-3-8- $\mathrm{H}_{2} \mathrm{O}-$ out.
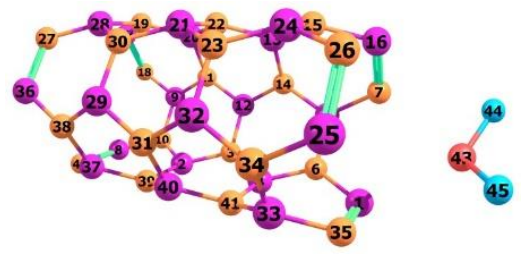

\begin{tabular}{|c|c|}
\hline Donor $\rightarrow$ acceptor & $\boldsymbol{E}_{2}$ \\
\hline $\boldsymbol{\pi}_{\mathrm{B} 16-\mathrm{N} 7} \rightarrow \sigma^{*}{ }^{*} 43-\mathrm{H} 44$ & 2.17 \\
\hline$\sigma \mathrm{O} 43-\mathrm{H} 45 \rightarrow \boldsymbol{\pi}^{*}{ }_{\mathrm{B} 25-\mathrm{N} 26}$ & 1.66 \\
\hline $\mathrm{LP}_{\mathrm{O} 43} \rightarrow \boldsymbol{\pi}_{\mathrm{B} 1-\mathrm{N} 35}$ & 3.98 \\
\hline $\mathrm{LP}_{043} \rightarrow \pi^{*}{ }_{\text {B25-N26 }}$ & 1.09 \\
\hline
\end{tabular}

